\title{
Stress, anxiety, and depression among medical students in a multiethnic setting
}

\author{
This article was published in the following Dove Press journal: \\ Neuropsychiatric Disease and Treatment \\ 16 July 2015 \\ Number of times this article has been viewed
}

\author{
Bibi Kulsoom' \\ Nasir Ali Afsar ${ }^{2}$ \\ 'Department of Biochemistry, \\ ${ }^{2}$ Department of Pharmacology, \\ College of Medicine, Alfaisal \\ University, Riyadh, Saudi Arabia
}

Correspondence: Nasir Ali Afsar Department of Pharmacology, College of Medicine, Alfaisal University, PO Box 50927, Al-Maather, Riyadh, Saudi Arabia Tel+966 II 2157679

Email nafsar@alfaisal.edu
Background: Contemporary literature suggests that medical education might adversely affect students' mental health. Alfaisal University in Riyadh, Saudi Arabia is a developing institution; hence, there has been a concern regarding the mental well-being of the students.

Objectives: This study was designed to assess the traits of depression, anxiety, and stress among students in relation to potential underlying reasons.

Methods: All 575 medical students across the 5 years of study participated by filling out the Depression, Anxiety, and Stress Scale-21 (DASS-21) questionnaire anonymously twice. Firstly, 2-3 weeks before a major examination (pre-examination), and secondly, during regular classes (post-examination). Correlation was sought regarding sex, year of scholarship, attendance of a premedical university preparatory program (UPP), housing, and smoking. Subjective comments from students were also obtained.

Results: A total of $76.8 \%$ and $74.9 \%$ of students participated in pre- and post-examination groups, respectively. The majority were the children of expatriate workers in Saudi Arabia, and included Arabs, South Asians, and North Americans. Prevalence of depression, anxiety, and stress was high $(43 \%, 63 \%$, and $41 \%$, respectively) which reduced (to $30 \%, 47 \%$, and $30 \%$, respectively) to some extent after examinations. Saudis and those who had attended UPP had higher DASS-21 scores. Smoking and female sex predicted higher levels of "baseline" depression, anxiety, or stress. The students perceived the curriculum and schedule to be the primary causes of their high DASS-21 scores.

Conclusion: The students had high "baseline" traits of depression, anxiety, and stress, and these were higher if an examination was near, especially among Saudis and those who had attended UPP. Smoking and female sex predicted higher levels of "baseline" depression, anxiety, or stress. Students suggested that study burden and a busy schedule were the major reasons for their high DASS-21 scores.

Keywords: DASS, examination, medical education, smoking, depression, anxiety, stress

\section{Introduction}

Mental health is regarded as an essential component of health by the World Health Organization. A person could be termed depressed if he/she shows a variable combination of low mood; loss of interest or pleasure; feelings of guilt; low self-esteem; disturbed appetite; disturbed sleep; or disturbed concentration. ${ }^{1}$

The American Psychological Association characterizes anxiety and stress ${ }^{2,3}$ by feelings of tension, worried thoughts, and physical changes. Anxiety is more related to autonomic arousal, skeletal muscle tension, and situational aspects, whereas stress is more related to irritability, impatience, and difficulty in relaxing.

Undergraduate medical education comprises strenuous study and training for 5-6 years. The curricular objectives are dynamic due to expanding knowledge and evolving therapies. During this period, medical students should acquire adequate 
professional knowledge, skill, and attitudes in order to prepare themselves to deal with life-long professional challenges independently. However, the demands of the learning and training might adversely affect the student's physical and mental health. It has been reported that medical students consequently suffer from depression, anxiety, and stress. ${ }^{4-6}$ Yusoff et $\mathrm{al}^{7}$ have previously reported that healthy students develop depression and stress after commencing their medical education. The competition for getting postgraduate training and job opportunities could be an additional trigger for psychological illness. It has also been reported that physicians tend to have a higher suicidal rate than the general population. $^{8}$

The subject has been studied in many countries; however, the student population in Middle East is still understudied. The government in Saudi Arabia puts emphasis on observing morality in society as well as promoting and facilitating the practice of religion. Islam, the predominant religion in the country, advocates honesty and hard work, and educates its followers to remain optimistic and peaceful in all circumstances. The crime rate is also among the lowest in the world. ${ }^{9}$ Thus, it could be assumed that the prevalence of depression, anxiety, or stress should be lower than other contemporary societies.

The Saudi Arabian economy is largely tax-free and has a high gross domestic product. Thus, it draws skilled and non-skilled labor from all parts of the world. However, the naturalization prospects for non-Saudis are almost nonexistent. The public-sector institutions prioritize Saudi citizens for professional education. Hence, non-Saudi expatriate workers living in the kingdom only have the provision of private-sector institutions, such as ours, should they wish their children to pursue higher education. Since the students get admission after rigorous competition and can afford to pay for their fees, this could translate into a sound academic record and being financially well-off. Presumably, this may further favor lower levels of depression, anxiety, or stress.

The students are generally supported as well as supervised by their parents or guardians in terms of sustenance, nurture, and education. This trend is further consolidated by prohibition of work permits to dependent children of foreign workers in the country. Like many societies in the Middle East and South Asia, youth, especially females, do not live independently from their families. Thus, they usually live with their guardians. Presumably, this could confer a sense of security and thus psychological well-being.

A recent report has suggested that cigarette smoking is on the rise among youth in Saudi Arabia. A number of studies have identified the pattern, predictors, and characteristics of tobacco smoking among local youth. ${ }^{10}$ Smoking, the largest cause of preventable death, has also been associated with stress, anxiety, and depression. Conversely, it has been noted that periods of stress lead to increased smoking prevalence. ${ }^{11}$ Similarly, smoking also increases stress, anxiety, and depression ${ }^{12-14}$ as well as "externalizing" behavior. ${ }^{14}$ Thus, it potentially leads to a vicious cycle of escalating psychological illness and increased smoking.

Some recent large studies conducted in various cities of Saudi Arabia ${ }^{15-18}$ have suggested that stress, anxiety, or depression exists among medical students. Although these studies have inducted a large number of students (total $2,448)$, the subject is only partially addressed. Further, the participants were only Saudis and different tools were used to measure the mental well-being. Thus, the status of mental well-being as influenced by nationality, living conditions, sex, and smoking at a competitive, multiethnic setting like ours in Saudi Arabia remains unclear.

The College of Medicine at Alfaisal University, Riyadh, Saudi Arabia is a relatively new institution which offers medical training to all sexes and ethnicities. Although there are no international students, the institution consists of a vibrant mixture of nationalities from many countries and backgrounds owing to expatriates residing in the country. More than $99 \%$ of students are Muslims. The vast majority of them actively practice their religion. The issues pertaining to expatriates are similar regardless of their nationalities. Thus, to draw meaningful conclusions, all expatriate students were grouped as a single group to compare them with their Saudi counterparts.

The medical curriculum at Alfaisal consists of basic and clinical subjects complimenting each other in a gradient fashion. The learning methods include lectures, problem-based learning, laboratory sessions, and clinical rotations. A number of faculty members and students are also supported financially to undertake research at local, national, and international levels. The first batch of graduates is already seeking suitable residency and postgraduate positions in North America and Europe, and some students have already found suitable placements. The medical students of this university scored consistently higher than students from other Saudi medical colleges in recently conducted nationwide "Progress Tests" (organized by Qassim College of Medicine, Qassim University, Qassim, Saudi Arabia). Student research activity and publication is also higher than other Saudi medical institutions.

There has been concern regarding the mental health and well-being of the students as raised by a number of students 
and faculty at the College of Medicine, Alfaisal University at different fora. The hectic schedule, course burden, and ancillary courses are being considered as potential reasons for this perceived psychological pressure. This led us to design the present study to explore mental health status in our students.

There are several tools to appraise mental health. Among them, a short, reliable, and validated questionnaire called Depression, Anxiety, and Stress Scale-21 (DASS-21) is of particular importance. ${ }^{19}$ This tool can identify traits of depression, anxiety, and stress rather than actual diagnosis. ${ }^{20}$ The DASS-21 questionnaire ${ }^{21}$ categorizes each condition into five subcategories, namely, normal, mild, moderate, severe, and extremely severe, as given in Table 1.

We designed this study to assess the level of depression, anxiety, and stress among medical students at Alfaisal University, and to identify possible correlates such as sex, nationality, year of scholarship, housing, and smoking.

\section{Materials and methods}

All medical students in basic (years 1, 2, and 3) as well as clerkship (years 4 and 5) phases of the academic year 2012-2013 were administered the DASS-21 questionnaire. The responses were sought in a self-reported, anonymous fashion. Since admission to medical college was open only for male students in the senior batches (years 3, 4, and 5 in the current study), the female students were available only in years 1 and 2 .

The inclusion of the subjects was anonymous and voluntary. All participants were included after an implied and/or verbal informed consent. The students were given printed written information and procedure of consent along with the DASS-21 questionnaire. Since the identity of the students remained undisclosed, no signature of participants was necessary. Rather, filling out the questionnaire and submission by the student himself/herself was considered as a declaration of willingness to participate. The ethical approval was obtained from The Committee for Medical and Bioethics, Office of Research and Graduate Studies, Alfaisal University.

Table I The categorization scores of the Depression, Anxiety, and Stress Scale-2I questionnaire

\begin{tabular}{llllll}
\hline Domain & Normal & Mild & Moderate & Severe & $\begin{array}{l}\text { Extremely } \\
\text { severe }\end{array}$ \\
\hline Depression & $0-9$ & $10-13$ & $14-20$ & $21-27$ & $\geq 28$ \\
Anxiety & $0-7$ & $8-9$ & $10-14$ & $15-19$ & $\geq 20$ \\
Stress & $0-14$ & $15-18$ & $19-25$ & $26-33$ & $\geq 34$ \\
\hline
\end{tabular}

To facilitate meaningful analysis, we categorized the students into two broad groups. The "normal" and "mild positive" scores for each category of DASS-21were considered as a single group, whereas the "moderate" and "severe" positive scores for each category were grouped together.

In addition to DASS-21, information was sought regarding sex; year of study; attendance of a premedical university preparatory program (UPP); housing and living; smoking; and use of any recreational drugs. An additional open-ended section was included to allow students to reflect on the reason/reasons, if any, for their choices in DASS-21. The data from the open-ended section were grouped based on common themes.

The questionnaire was administered at two time-points for all students, as follows: 1) 2-3 weeks before a major terminal examination at the end of a semester (thus referred to as "Pre-Exam"); and 2) during regular classes in the following semester (thus referred to as "Post-Exam").

The independent factors included sex, nationality, year of scholarship, housing, and smoking. The dependent factors were Pre-Exam DASS-21 scores, Post-Exam DASS-21 scores, and the difference between them. The results were analyzed through one-way analysis of variance, chi-square tests, or multiple linear regression where appropriate, using SPSS version 21 (IBM Corporation, Armonk, NY, USA). Only a $P$-value of less than 0.05 was considered statistically significant.

\section{Results}

The medical students in all 5 years were administered the DASS-21 questionnaire in a Pre-Exam and Post-Exam fashion. The total number of registered students was 575 . The Cronbach's alpha was 0.92 . Table 2 describes the baseline characteristics of the study population. A total of 442 (76.8\%) students participated in the Pre-Exam group whereas 431 (74.9\%) participated in Post-Exam group. Since student admissions had increased over recent years, the most senior batch had the least absolute numbers, but they had a proportionate representation.

Overall, the proportion of expatriate students was higher than the Saudi citizens. The expatriates largely ( $>90 \%)$ included citizens from neighboring Arab states (Syria, Jordan, Palestine, and Egypt), South Asia (Pakistan, Bangladesh, and India), and North America (Canada and USA). The majority of students lived with parents. The majority of students declared that they were nonsmokers.

Table 3 describes the relationship of different variables with mean DASS-21 scores. The scores for depression, 
Table 2 Baseline characteristics of the study population

\begin{tabular}{|c|c|c|c|c|}
\hline \multirow[t]{2}{*}{ Parameters } & \multicolumn{2}{|c|}{ Pre-examination } & \multicolumn{2}{|c|}{ Post-examination } \\
\hline & Frequency & Percent & Frequency & Percent \\
\hline \multicolumn{5}{|l|}{ Sex } \\
\hline Male & 274 & 62 & 280 & 65 \\
\hline Female & 168 & 38 & $|5|$ & 35 \\
\hline Total & 442 & 100 & 431 & 100 \\
\hline \multicolumn{5}{|c|}{ Nationality being Saudi or non-Saudi } \\
\hline Saudi & 156 & 35.3 & 173 & 40.1 \\
\hline Non-Saudi & 198 & 44.8 & 217 & 50.3 \\
\hline Undetermined & 88 & 19.9 & 41 & 9.5 \\
\hline Total & 442 & 100 & 431 & 100 \\
\hline \multicolumn{5}{|c|}{ University preparatory program } \\
\hline Attended & 210 & 47.5 & 198 & 45.9 \\
\hline Did not attend & 211 & 47.7 & 219 & 50.8 \\
\hline Undetermined & 21 & 4.8 & 14 & 3.2 \\
\hline Total & 442 & 100 & 431 & 100 \\
\hline \multicolumn{5}{|c|}{ Enrollment at the time of study } \\
\hline MBBS year I & 175 & 39.5 & 169 & 39.2 \\
\hline MBBS year 2 & 148 & 33.5 & 158 & 36.7 \\
\hline MBBS year 3 & 67 & 15.2 & 60 & 13.9 \\
\hline MBBS year 4 & 30 & 6.8 & 20 & 4.6 \\
\hline MBBS year 5 & 22 & 5 & 24 & 5.6 \\
\hline Total & 442 & 100 & 431 & 100 \\
\hline \multicolumn{5}{|l|}{ Housing } \\
\hline Parents/family & 348 & 78.7 & 362 & 84 \\
\hline Relatives & 12 & 2.7 & 14 & 3.2 \\
\hline Alone & 52 & 11.8 & 45 & 10.4 \\
\hline Undetermined & 30 & 6.8 & 10 & 2.3 \\
\hline Total & 442 & 100 & 431 & 100 \\
\hline \multicolumn{5}{|l|}{ Smoking status } \\
\hline Nonsmoker & 367 & 83 & 365 & 84.7 \\
\hline $\begin{array}{l}\text { Occasional } \\
\text { smoker }\end{array}$ & 27 & 6.1 & 28 & 6.5 \\
\hline $\begin{array}{l}\text { Regular } \\
\text { smoker }\end{array}$ & 27 & 6.1 & 29 & 6.7 \\
\hline Undetermined & 21 & 4.8 & 8 & 1.9 \\
\hline Total & 442 & 100 & 431 & 100 \\
\hline \multicolumn{5}{|c|}{ Addiction other than smoking } \\
\hline Undeclared & 376 & 85.1 & 384 & 89.1 \\
\hline None & 64 & 14.5 & 38 & 8.8 \\
\hline Multiple & 2 & 0.5 & I & 0.2 \\
\hline Coffee/tea & 0 & 0 & 6 & 1.4 \\
\hline Chocolate & 0 & 0 & 2 & 0.5 \\
\hline Total & 442 & 100 & 431 & 100 \\
\hline
\end{tabular}

anxiety, and stress were significantly higher in the Pre-Exam group. Students in year 4 had the highest level of depression, anxiety, and stress. The DASS-21 scores were also higher among Saudis, students who attended a year of UPP before commencing their medical curriculum, and the regular smokers. Housing and sex did not appear to be associated with depression, anxiety, or stress scores.

Table 4 presents the prevalence (percent, frequency) of depression, anxiety, and stress and its variation with an impending examination. Anxiety was significantly higher if the examination was approaching. Although the depression and stress also increased with an approaching examination, statistical significance was not achieved. However, it is noteworthy that the "baseline" levels (Post-Exam) of all three were already high.

Table 5 presents the multiple linear regression conducted to further analyze the data. The study population was divided in two, ie, Pre-Exam and Post-Exam groups. The total DASS-21 score was considered as the dependent variable while the independent variables included sex (male or female), nationality (Saudi, Non-Saudi), attendance of a UPP (attended or not), academic year in MBBS program (year 1-5), housing (with parents, with relatives, or alone), and smoking status. The $F$ statistic was $2.84(P=0.01)$ and $2.71(P=0.01)$, for the PreExam and Post-Exam groups, respectively. The standardized coefficient Beta, $t$ statistic, significance level ( $P$-value), and 95\% confidence intervals are given. The Pre-Exam group showed that DASS-21 scores increase (predicts $21.5 \%$ of this phenomenon) with advancing years in MBBS program, while in the PostExam group, DASS-21 score is mainly influenced by regular smoking (16\%) and female sex (11.3\%). It should be noted that DASS-21 scores are lower in the Post-Exam group.

Table 6 presents the comments given by the students. Only $12.3 \%$ and $9 \%$ of students from Pre-Exam and PostExam groups, respectively, wrote reasons which they perceived to be responsible for their feelings. The data shows frequency (n) of the responses falling under a theme. In the majority of instances, the examinations, course burden, and hectic schedule was regarded as the reason for their depression, anxiety, or stress. The shift in frequency in the two groups is self-explanatory.

\section{Discussion}

The main results of this study suggest that among medical students at Alfaisal University, there is a high "baseline" level of depression, anxiety, and stress, which tends to remain much higher if a major examination is near. Smoking and female sex appears to predict higher levels of depression, anxiety, or stress in the absence of an impending examination. The students perceive the course burden and hectic schedule as the most important reasons underlying their high DASS-21 scores.

To the best of our knowledge, this study was the largest in the kingdom where both Saudi and expatriate students were included. Further, we studied traits of depression, anxiety, and stress while most of the others had reported fewer parameters. We also studied the DASS-21 scores at two different time-points to see the variation among medical students. 
Table 3 Depression, Anxiety, and Stress Scale-2I scores between the pre-examination and post-examination cohorts

\begin{tabular}{|c|c|c|c|c|c|c|}
\hline Variables and groups & $\mathbf{N}$ & Mean & SD & $\begin{array}{l}\text { Levene's } \\
\text { statistic }\end{array}$ & $F$ & $P$ \\
\hline \multicolumn{7}{|l|}{ Timing of examination } \\
\hline \multicolumn{7}{|l|}{ Depression score } \\
\hline Pre-exam & 442 & 6.65 & 5.39 & 0.001 & 24.20 & $<0.001$ \\
\hline Post-exam & 431 & 4.98 & 4.62 & & & \\
\hline Total & 873 & 5.83 & 5.09 & & & \\
\hline \multicolumn{7}{|l|}{ Anxiety score } \\
\hline Pre-exam & 442 & 6.87 & 4.69 & 0.06 & 30.44 & $<0.001$ \\
\hline Post-exam & 431 & 5.19 & 4.28 & & & \\
\hline Total & 873 & 6.04 & 4.56 & & & \\
\hline \multicolumn{7}{|l|}{ Stress score } \\
\hline Pre-exam & 442 & 8.79 & 5.20 & 0.13 & 19.41 & $<0.001$ \\
\hline Post-exam & 431 & 7.28 & 4.88 & & & \\
\hline Total & 873 & 8.04 & 5.10 & & & \\
\hline \multicolumn{7}{|l|}{ Year of enrolment } \\
\hline \multicolumn{7}{|l|}{ Depression score } \\
\hline Year I & 492 & 5.59 & 5.11 & 0.15 & 3.97 & 0.003 \\
\hline Year 2 & 225 & 5.46 & 4.63 & & & \\
\hline Year 3 & 90 & 6.63 & 5.43 & & & \\
\hline Year 4 & 42 & 8.40 & 5.78 & & & \\
\hline Year 5 & 24 & 6.54 & 4.95 & & & \\
\hline Total & 873 & 5.83 & 5.09 & & & \\
\hline \multicolumn{7}{|l|}{ Anxiety score } \\
\hline Year I & 492 & 6.14 & 4.55 & 0.13 & 3.33 & 0.01 \\
\hline Year 2 & 225 & 5.34 & 4.25 & & & \\
\hline Year 3 & 90 & 6.60 & 4.70 & & & \\
\hline Year 4 & 42 & 7.79 & 5.38 & & & \\
\hline Year 5 & 24 & 5.58 & 4.83 & & & \\
\hline Total & 873 & 6.04 & 4.56 & & & \\
\hline \multicolumn{7}{|l|}{ Stress score } \\
\hline Year I & 492 & 8.04 & 5.16 & 0.19 & 2.20 & 0.067 \\
\hline Year 2 & 225 & 7.50 & 4.77 & & & \\
\hline Year 3 & 90 & 9.08 & 5.20 & & & \\
\hline Year 4 & 42 & 9.17 & 5.63 & & & \\
\hline Year 5 & 24 & 7.33 & 5.06 & & & \\
\hline Total & 873 & 8.04 & 5.10 & & & \\
\hline \multicolumn{7}{|l|}{ Saudi versus non-Saudi } \\
\hline \multicolumn{7}{|l|}{ Depression score } \\
\hline Saudi & 329 & 5.80 & 5.08 & 0.69 & 0.62 & 0.43 \\
\hline Non-Saudi & 415 & 5.51 & 4.93 & & & \\
\hline Total & 744 & 5.64 & 4.99 & & & \\
\hline \multicolumn{7}{|l|}{ Anxiety score } \\
\hline Saudi & 329 & 6.27 & 4.61 & 0.94 & 5.73 & 0.02 \\
\hline Non-Saudi & 415 & 5.48 & 4.31 & & & \\
\hline Total & 744 & 5.83 & 4.46 & & & \\
\hline \multicolumn{7}{|l|}{ Stress score } \\
\hline Saudi & 329 & 8.36 & 5.10 & 0.23 & 6.67 & 0.01 \\
\hline Non-Saudi & 415 & 7.42 & 4.81 & & & \\
\hline Total & 744 & 7.84 & 4.96 & & & \\
\hline \multicolumn{7}{|c|}{ Attended university preparatory program } \\
\hline \multicolumn{7}{|l|}{ Depression score } \\
\hline Yes & 408 & 6.04 & 5.13 & 0.39 & 3.11 & 0.08 \\
\hline No & 430 & 5.43 & 4.85 & & & \\
\hline Total & 838 & 5.73 & 5.00 & & & \\
\hline \multicolumn{7}{|l|}{ Anxiety score } \\
\hline Yes & 408 & 6.29 & 4.75 & 0.04 & 4.39 & 0.04 \\
\hline No & 430 & 5.64 & 4.14 & & & \\
\hline Total & 838 & 5.96 & 4.46 & & & \\
\hline
\end{tabular}


Table 3 (Continued)

\begin{tabular}{|c|c|c|c|c|c|c|}
\hline Variables and groups & $\mathbf{N}$ & Mean & SD & $\begin{array}{l}\text { Levene's } \\
\text { statistic }\end{array}$ & $F$ & $P$ \\
\hline \multicolumn{7}{|l|}{ Stress score } \\
\hline Yes & 408 & 8.19 & 4.97 & 0.95 & 1.74 & 0.19 \\
\hline No & 430 & 7.73 & 5.02 & & & \\
\hline Total & 838 & 7.95 & 5.00 & & & \\
\hline \multicolumn{7}{|l|}{ Housing conditions } \\
\hline \multicolumn{7}{|l|}{ Depression score } \\
\hline Parents/family & 710 & 5.75 & 5.07 & 0.37 & 1.31 & 0.27 \\
\hline Relatives & 26 & 4.27 & 4.69 & & & \\
\hline Alone & 97 & 6.06 & 4.77 & & & \\
\hline Total & 833 & 5.74 & 5.02 & & & \\
\hline \multicolumn{7}{|l|}{ Anxiety score } \\
\hline Parents/family & 710 & 5.90 & 4.49 & 0.52 & 0.36 & 0.69 \\
\hline Relatives & 26 & 5.62 & 3.83 & & & \\
\hline Alone & 97 & 6.28 & 4.59 & & & \\
\hline Total & 833 & 5.94 & 4.48 & & & \\
\hline \multicolumn{7}{|l|}{ Stress score } \\
\hline Parents/family & 710 & 7.98 & 5.06 & 0.52 & 0.57 & 0.56 \\
\hline Relatives & 26 & 7.19 & 4.39 & & & \\
\hline Alone & 97 & 8.35 & 4.93 & & & \\
\hline Total & 833 & 8.00 & 5.02 & & & \\
\hline \multicolumn{7}{|l|}{ Sex } \\
\hline \multicolumn{7}{|l|}{ Depression score } \\
\hline Male & 554 & 5.92 & 5.09 & 0.79 & 0.49 & 0.48 \\
\hline Female & 319 & 5.67 & 5.10 & & & \\
\hline Total & 873 & 5.83 & 5.09 & & & \\
\hline \multicolumn{7}{|l|}{ Anxiety score } \\
\hline Male & 554 & 6.05 & 4.65 & 0.33 & 0.01 & 0.94 \\
\hline Female & 319 & 6.03 & 4.42 & & & \\
\hline Total & 873 & 6.04 & 4.56 & & & \\
\hline \multicolumn{7}{|l|}{ Stress score } \\
\hline Male & 554 & 7.96 & 5.12 & 0.76 & 0.42 & 0.52 \\
\hline Female & 319 & 8.19 & 5.06 & & & \\
\hline Total & 873 & 8.04 & 5.10 & & & \\
\hline \multicolumn{7}{|l|}{ Smoking status } \\
\hline \multicolumn{7}{|l|}{ Depression score } \\
\hline Nonsmoker & 732 & 5.60 & 4.88 & $<0.001$ & 4.01 & 0.01 \\
\hline Occasional & 55 & 6.35 & 4.84 & & & \\
\hline Regular & 56 & 7.93 & 6.64 & & & \\
\hline Total & 843 & 5.80 & 5.04 & & & \\
\hline \multicolumn{7}{|l|}{ Anxiety score } \\
\hline Nonsmoker & 732 & 5.83 & 4.36 & 0.04 & 4.41 & 0.004 \\
\hline Occasional & 55 & 6.87 & 3.98 & & & \\
\hline Regular & 56 & 7.86 & 6.07 & & & \\
\hline Total & 843 & 6.03 & 4.49 & & & \\
\hline \multicolumn{7}{|l|}{ Stress score } \\
\hline Nonsmoker & 732 & 7.93 & 4.98 & 0.002 & 1.80 & 0.14 \\
\hline Occasional & 55 & 8.00 & 3.96 & & & \\
\hline Regular & 56 & 9.55 & 6.36 & & & \\
\hline Total & 843 & 8.05 & 5.03 & & & \\
\hline
\end{tabular}

Abbreviations: exam, examination; SD, standard deviation.

\section{Relationship of DASS-2I scores with assessment}

We found that students would be highly stressed, anxious, and depressed if an examination was approaching. This is in accordance with multiple previous studies on this subject done elsewhere. Only some have attempted to undertake an in-depth analysis. It appears that method and assessment grading systems affects student well-being more than any other component of the curriculum. Further, it has been reported that the greater the number of grading scale categories, the 
Table 4 Prevalence (percent) of moderate or severe depression, anxiety, and stress in the pre- and post-examination cohorts

\begin{tabular}{llll}
\hline $\begin{array}{l}\text { Variables } \\
\text { and groups }\end{array}$ & $\begin{array}{c}\text { Normal } \\
\text { or mild }\end{array}$ & $\begin{array}{l}\text { Moderate } \\
\text { or severe }\end{array}$ & $\mathbf{P}^{*}$ \\
\hline \multicolumn{2}{l}{ Timing of examination } & & \\
Depression & & & \\
$\quad$ Pre-exam & 57 & 43 & 0.05 \\
$\quad \begin{array}{l}\text { Post-exam } \\
\text { Anxiety score }\end{array}$ & 70 & 30 & 0.02 \\
$\quad$ Pre-exam & 37 & 63 & \\
$\quad$ Post-exam & 53 & 47 & 0.1 \\
Stress score & & & \\
$\quad$ Pre-exam & 59 & 41 & \\
Post-exam & 70 & 30 & \\
\hline
\end{tabular}

Notes: *P-value calculated through chi-square test. "Includes extremely severe depression. Abbreviation: exam, examination.

higher the level of stress and emotional exhaustion. A similar effect is seen if examinations take place frequently. ${ }^{22} \mathrm{Also}$, in the case of our students, the grading system comprised multiple categories, ie, grade $\mathrm{A}+, \mathrm{A}, \mathrm{A}-, \mathrm{B}+, \mathrm{B}, \mathrm{B}-$, and so on. A number of students are awarded scholarships annually, which is tied to their consistent high performance in examinations. It is possible that this setup is contributing to their high level of depression, anxiety, or stress. As presented in Table 5, many students have attributed their condition either to difficulty in coping with their studies, or fear of failure or losing their scholarship. It is quite possible that the high prevalence of depression, anxiety, or stress could lead to burnout among them and thereby affect their performance, progress, or personal life in the long-term, thus requiring a follow up study.

\section{Relationship of DASS-2I scores with level of scholarship}

Like many other countries, in Saudi Arabia, the students are admitted to medical college after completing 12 years of school education. Transition from a high school or college to a professional career is a big jump. It is no wonder 1st year medical students feel stress due to greater work load. ${ }^{23}$ Similarly, the commencement of a hospital or practical phase of their career has its own demands. Higher levels of depression have been reported during internship and residency due to non-supportive and highly challenging environments as compared to other undergraduate years. ${ }^{23,24}$ In the current study, although there was high stress among 1st year students, it peaked in year 4 , where the clerkship phase starts and students rotate through various disciplines of hospital as their major method of training. We also found that year $4 \mathrm{had}$ the highest depression and anxiety scores. Thus, this agrees with other similar studies elsewhere..$^{23,24}$

\section{Relationship of DASS-2I scores with nationality}

Mental health has been studied in various parts of the world. The baseline levels of stress, anxiety, and depression could vary due to different social, economic, and personal factors, and thus, these factors should affect the results of such studies. However, studies from the Middle East in general, and Saudi Arabia in particular, are a recent phenomenon. In a recent study ${ }^{15}$ conducted simultaneously in Saudi Arabia and Egypt by a single team, it was concluded that Saudi students had lower anxiety and depression than their Egyptian counterparts. However, the students were studied in their respective home countries. In our study of students in the same setting, we found that Saudi students were more anxious and stressed than their expatriate counterparts. A number of studies done in various state-run medical colleges in the kingdom have reported high prevalence of depression, anxiety, or stress,

Table 5 Multiple linear regression: pre- and post-examinations

\begin{tabular}{|c|c|c|c|c|c|}
\hline \multirow[t]{2}{*}{$\overline{\text { Model }}$} & \multirow{2}{*}{$\begin{array}{l}\text { Coefficient } \\
\text { beta }\end{array}$} & \multirow[t]{2}{*}{$t$} & \multirow[t]{2}{*}{ Sig } & \multicolumn{2}{|c|}{$95 \% \mathrm{Cl}$ for beta } \\
\hline & & & & Lower & $\overline{\text { Upper }}$ \\
\hline Pre-exam & & 3.017 & 0.003 & 5.802 & 27.544 \\
\hline Sex & 0.072 & 1.140 & 0.255 & -1.418 & 5.323 \\
\hline Nationality & -0.081 & -1.397 & 0.163 & -5.189 & 0.879 \\
\hline Attended UPP & -0.038 & -0.691 & 0.490 & -3.903 & 1.875 \\
\hline Academic year & 0.215 & 3.506 & 0.001 & 1.846 & 6.568 \\
\hline Housing & -0.033 & -0.573 & 0.567 & -2.884 & 1.583 \\
\hline Smoking status & 0.071 & 1.257 & 0.210 & -1.082 & 4.909 \\
\hline Post-exam & & 2.743 & 0.006 & 3.416 & 20.728 \\
\hline Sex & 0.113 & 2.002 & 0.046 & 0.049 & 5.552 \\
\hline Nationality & -0.069 & -1.288 & 0.198 & -4.180 & $0.87 \mid$ \\
\hline Attended UPP & -0.055 & -1.050 & 0.294 & -3.763 & 1.143 \\
\hline Academic year & 0.040 & 0.733 & 0.464 & -0.784 & 1.715 \\
\hline Housing & 0.013 & 0.245 & 0.806 & -1.692 & 2.175 \\
\hline Smoking status & 0.160 & 2.978 & 0.003 & 1.240 & 6.063 \\
\hline
\end{tabular}

Abbreviations: exam, examination; UPP, university preparatory program. 
Table 6 The reasons as perceived by the students leading to depression, anxiety, or stress

\begin{tabular}{lll}
\hline $\begin{array}{l}\text { Suggested reasons for } \\
\text { higher stress, anxiety, } \\
\text { or depression }\end{array}$ & $\begin{array}{l}\text { Pre-examination } \\
\text { (frequency) }\end{array}$ & $\begin{array}{l}\text { Post-examination } \\
\text { (frequency) }\end{array}$ \\
\hline $\begin{array}{l}\text { Examinations } \\
\text { Difficulty in coping }\end{array}$ & 29 & 10 \\
with studies & 22 & 3 \\
Social issues/bad thoughts & 5 & 17 \\
Bad schedule & 5 & $\mathrm{II}$ \\
Boredom & 4 & 4 \\
Exhaustion & 3 & $\mathrm{I}$ \\
Lack of a counselor/support & 3 & $\mathrm{I}$ \\
Fear of losing scholarship & 2 & 2 \\
Smoking/addiction/habits & 2 & 3 \\
Environment/climate/ & 0 & 4 \\
transportation & & \\
\hline
\end{tabular}

where the students are primarily Saudi nationals. ${ }^{15-18}$ The results are compared in Table 7.

\section{Relationship of DASS-2I scores with preadmission grades}

Those students who were admitted to medicine after a yearlong UPP had higher anxiety levels. At Alfaisal University, a student may get direct admission if his/her grades are above a certain threshold. Thus, it could be inferred, albeit indirectly, that among those who had better preadmission qualifying grades, enabling a direct admission to the medical college (without UPP), there were lower anxiety levels. Out of the direct admissions, approximately $60 \%$ were expatriates. Whether this is the reason for higher DASS-21 scores among Saudi students, needs further research.

\section{Relationship of DASS-2I scores with sex and living conditions}

Some previous studies have concluded that female students are more likely to experience depression ${ }^{23-25}$ and female physicians tend to have higher suicide rates than their male colleagues. ${ }^{8}$ In our study, the logistic regression (Table 4) suggested that Females tends to have a significantly higher
DASS-21 score only in the Post-Exam group. It could be possible that an overall higher DASS-21 score masked this phenomenon in the Pre-Exam group.

In our study, the majority of students lived with their parents. However, there were students (15\%) who either lived alone or with relatives. Although the levels of depression, anxiety, and stress were highest among those who lived alone, it did not reach statistical significance.

\section{Relationship of DASS-2I scores with tobacco smoking}

In our study, there was a strong positive relationship of regular smoking with depression and anxiety. However, a cause-effect relationship cannot be drawn from this study. While it could be considered to confirm earlier observations, the proportion of reported smokers among the study sample was small. This aspect requires further exploration in future studies.

\section{Long-term effects of psychological problems among health professionals}

Depression is considered a stigma for medical students as this could be perceived as detrimental to their professional and personal life. It is observed that the medical students suffering from depression feel guilty about sharing their emotional state with others, or are reluctant to receive treatment. ${ }^{26,27}$ A recent review suggested that ignoring one's psychological problem could lead to serious consequences. ${ }^{28}$ Unfortunately, medical students experience suicidal thoughts and ideas because of depression, anxiety, and other reasons. ${ }^{29}$ Further, burnout and chronic stress have also been found to correlate strongly with professional misconduct or reduced altruistic values among physicians. ${ }^{30}$ This is a serious consequence not only for the health professionals but also for society. At present, we cannot confirm or reject such extreme ideation and their consequences in our setting. Whether religious teachings and culture play any preventive role in this regard is also difficult to ascertain. At least a few of the

Table 7 Comparison of mental health status among medical students in recent local studies

\begin{tabular}{|c|c|c|c|c|c|c|}
\hline Study & Country (city) & Questionnaire & $\mathbf{N}(\operatorname{sex})$ & Depression \% & Anxiety \% & Stress \% \\
\hline Current study & Saudi Arabia (Riyadh) & DASS-2I & $873(\mathrm{M}$ and $\mathrm{F})$ & $30-43$ & $47-63$ & $30-41$ \\
\hline Ibrahim et al $(2013)^{16}$ & Saudi Arabia (Jeddah) & HADS & $450(F)$ & 14.7 & 34.9 & Not tested \\
\hline Al-Faris et al $(2012)^{17}$ & Saudi Arabia (Riyadh) & BDI & 794 ( $M$ and $F$ ) & 48.2 & Not tested & Not tested \\
\hline Al-Dabal et al $(2010)^{18}$ & Saudi Arabia (Dammam) & ISSH & $616(F)$ & Not tested & Not tested & 48.6 \\
\hline El-Gilany et al $(2008)^{15}$ & Saudi Arabia (Al-Hassa); & CPSS; HADS & $588(M)$ & 16.2 & 15.5 & 28.9 \\
\hline
\end{tabular}

Abbreviations: BDI, Beck Depression Inventory (2I items); CPSS, Cohen's Perceived Stress Scale; DASS-2I, Depression, Anxiety, and Stress Scale-2I; F, female; HADS, Hospital Anxiety \& Depression Scale; ISSH, Influence of Studying on Students' Health; M, male. 
students' comments hinted that they tend to remain content and patient in accordance with religious teachings. Further studies are needed to answer these questions.

\section{Advantages of this study}

The study is important in several ways. Firstly, it was conducted in a multiethnic cohort. Secondly, it gauges the prevalence of depression, anxiety, or stress among medical students in all 5 years at Alfaisal University, which is a leading institution in the Kingdom of Saudi Arabia. Thirdly, it compares simultaneously the DASS-21 scores in relation to sex, nationality, smoking status, and other possible underlying reasons in this culture. Fourthly, the sample size is large and adequately represents the students in all 5 years from basic sciences to clerkship phases.

\section{Limitations of this study}

There are some limitations of this study. Firstly, the data on depression, anxiety, or stress among the study cohort before the commencement of medical education is not available. Secondly, the prevalence of depression, anxiety, or stress in the general population is also not available. Thirdly, the study tool depends upon self-reported measures. Fourthly, the majority of students did not report their status for smoking and recreational drug use; nor did they provide any descriptive comments about their perceived underlying reasons for their depression, anxiety, or stress. Finally, the anonymity of students made it impossible to check for any change of individual DASS-21 scores.

\section{Implications of this study}

There are some implications of the study. First, the unnecessary course burden and busy schedule could be rectified by devising a justified list of observable specific course objectives in all courses. The number of lectures could be reduced as continuous lecturing may not be helpful in retention of information. ${ }^{31}$ Second, as there is much emphasis on problembased learning, all possible care should be taken to avoid overlap of objectives to be covered in lectures and problembased learning sessions. This could "free" some space in the schedule for self-directed learning and reflection, which is an important aspect of learning. Third, regular feedback from faculty as well as students regarding the academics should be encouraged and considered. Fourth, the existing student mentorship program could be directed to address students' concerns. Fifth, time-management workshops could be conducted for students. Finally, efforts should be taken to discourage smoking among students.

\section{Conclusion}

Thus, we conclude that the medical students had high levels of traits of depression, anxiety, and stress. Anticipated examinations, attending UPP, smoking, and female sex were associated with higher levels of depression, anxiety, or stress among them. Students suggested that study burden and busy schedule were major reasons for their high scores.

\section{Acknowledgments}

The authors would like to thank Dr Peter MB Cahusac, Associate Professor, Department of Pharmacology, College of Medicine, Alfaisal University for his assistance in reviewing the English language of this manuscript. The authors highly appreciate the cooperation of all faculty and staff at Alfaisal University who kindly facilitated the collection of data for this study. We are very grateful to all the students who volunteered to participate and who gave their views.

\section{Disclosure}

The authors report no conflicts of interest in this work.

\section{References}

1. Marcus M, Yasamy MT, van Ommeren M, Chisholm D, Saxena S Depression, A Global Public Health Concern. Geneva: World Health Organization. Available from: www.who.int/mental_health/ management/depression/who_paper_depression_wfmh_2012.pdf. Accessed July 13, 2014.

2. Anxiety [webpage on the Internet]. American Psychological Association. Available from: http://www.apa.org/topics/anxiety/index. aspx. Accessed July 13, 2014.

3. Stress [webpage on the Internet]. American Psychological Association. Available from: http://www.apa.org/topics/stress/. Accessed July 13, 2014.

4. Henning K, Ey S, Shaw D. Perfectionism, the imposter phenomenon and psychological adjustment in medical, dental, nursing and pharmacy students. Med Educ. 1998;32:456-464.

5. Roberts LW, Warner TD, Lyketsos C, Frank E, Ganzini L, Carter D. Perceptions of academic vulnerability associated with personal illness: a study of 1,027 students at nine medical schools. Collaborative Research Group on Medical Student Health. Compr Psychiatry. 2001;42:1-15.

6. Dyrbye LN, Thomas MR, Eacker A, et al. Race, ethnicity, and medical student well-being in the United States. Arch Intern Med. 2007;167: 2103-2109.

7. Yusoff MS, Abdul Rahim AF, Baba AA, Ismail SB, Mat Pa MN, Esa AR The impact of medical education on psychological health of students: a cohort study. Psychol Health Med. 2013;18:420-430.

8. Schernhammer ES, Colditz GA. Suicide rates among physicians: a quantitative and gender assessment (meta-analysis). Am J Psychiatry. 2004; 161:2295-2302.

9. Crime Index 2014 Mid Year [webpage on the Internet]. Belgrade-Zvezdara: Numbio; 2015. Available from: www.numbeo.com/crime/gmaps rankings_country.jsp. Accessed August 12, 2014.

10. Al Moamary MS, Al Ghobain MO, Al Shehri SN, Gasmelseed AY, Al-Hajjaj MS. Predicting tobacco use among high school students by using the global youth tobacco survey in Riyadh, Saudi Arabia. Ann Thorac Med. 2012;7:122-129.

11. Pesko MF. Stress and smoking: associations with terrorism and causal impact. Contemp Econ Policy. 2014;32:351-371. 
12. Trosclair A, Dube SR. Smoking among adults reporting lifetime depression, anxiety, anxiety with depression, and major depressive episode, United States, 2005-2006. Addict Behav. 2010;35:438-443.

13. Mojtabai R, Crum RM. Cigarette smoking and onset of mood and anxiety disorders. Am J Public Health. 2013;103:1656-1665.

14. Whalen CK, Jamner LD, Henker B, Delfino RJ. Smoking and moods in adolescents with depressive and aggressive dispositions: evidence from surveys and electronic diaries. Health Psychol. 2001;20:99-111.

15. El-Gilany AH, Amr M, Hammad S. Perceived stress among male medical students in Egypt and Saudi Arabia: effect of sociodemographic factors. Ann Saudi Med. 2008;28:442-448.

16. Ibrahim N, Al-Kharboush D, El-Khatib L, Al-Habib A, Asali D. Prevalence and Predictors of Anxiety and Depression among Female Medical Students in King Abdulaziz University, Jeddah, Saudi Arabia. Iran J Public Health. 2013;42:726-736.

17. Al-Faris EA, Irfan F, Van der Vleuten CP, et al. The prevalence and correlates of depressive symptoms from an Arabian setting: a wake up call. Med Teach. 2012;34 Suppl 1:S32-S36.

18. Al-Dabal BK, Koura MR, Rasheed P, Al-Sowielem L, Makki SM. Comparative Study of Perceived Stress among Female Medical and Non-Medical University Students in Dammam, Saudi Arabia. Sultan Qaboos Univ Med J. 2010;10:231-240.

19. Henry JD, Crawford JR. The short-form version of the Depression Anxiety Stress Scales (DASS-21): construct validity and normative data in a large non-clinical sample. Br J Clin Psychol. 2005;44: 227-239.

20. Gloster AT, Rhoades HM, Novy D, et al. Psychometric properties of the Depression Anxiety and Stress Scale-21 in older primary care patients. $J$ Affect Disord. 2008;110:248-259.

21. Lovibond SH, Lovibond PF, editors. Manual for the Depression Anxiety Stress Scales. 2nd ed. Sydney: Psychology Foundation; 1995.
22. Reed DA, Shanafelt TD, Satele DW, et al. Relationship of pass/fail grading and curriculum structure with well-being among preclinical medical students: a multi-institutional study. Acad Med. 2011;86:1367-1373.

23. Dahlin M, Joneborg N, Runeson B. Stress and depression among medical students: a cross-sectional study. Med Educ. 2005;39:594-604.

24. Baldassin S, Alves TC, de Andrade AG, Nogueira Martins LA. The characteristics of depressive symptoms in medical students during medical education and training: a cross-sectional study. BMC Med Educ. 2008;8:60.

25. Alvi T, Assad F, Ramzan M, Khan FA. Depression, anxiety and their associated factors among medical students. J Coll Physicians Surg Pak. 2010;20:122-126.

26. Rosenthal JM, Okie S. White coat, mood indigo - depression in medical school. N Engl J Med. 2005;353:1085-1088.

27. Cheng DR, Poon F, Nguyen TT, Woodman RJ, Parker JD. Stigma and perception of psychological distress and depression in Australiantrained medical students: results from an inter-state medical school survey. Psychiatry Res. 2013;209:684-690.

28. Flannery-Schroeder EC. Reducing anxiety to prevent depression. Am J Prev Med. 2006;31(6 Suppl 1):S136-S142.

29. Schwenk TL, Davis L, Wimsatt LA. Depression, stigma, and suicidal ideation in medical students. JAMA. 2010;304:1181-1190.

30. Dyrbye LN, Massie FS Jr, Eacker A, Harper W, Power D, Durning SJ, et al. Relationship between burnout and professional conduct and attitudes among US medical students. JAMA. 2010;304:1173-1180.

31. Risko EF, Anderson N, Sarwal A, Engelhardt M, Kingstone A. Everyday Attention: Variation in Mind Wandering and Memory in a Lecture. Appl Cognit Psychol. 2012;26:234-242.
Neuropsychiatric Disease and Treatment

\section{Publish your work in this journal}

Neuropsychiatric Disease and Treatment is an international, peerreviewed journal of clinical therapeutics and pharmacology focusing on concise rapid reporting of clinical or pre-clinical studies on a range of neuropsychiatric and neurological disorders. This journal is indexed on PubMed Central, the 'PsycINFO' database and CAS,

\section{Dovepress}

and is the official journal of The International Neuropsychiatric Association (INA). The manuscript management system is completely online and includes a very quick and fair peer-review system, which is all easy to use. Visit http://www.dovepress.com/testimonials.php to read real quotes from published authors. 